\title{
Clinical Experience with Apatinib and Camrelizumab in Advance Clear Cell Sarcoma: A Retrospective Study
}

\author{
Jiaqiang Wang (D) \\ Shilei Gao' \\ Yonghao Yang ${ }^{2}$ \\ Xu Liu' \\ Peng Zhang' \\ Shuping Dong' \\ Xin Wang \\ Weitao Yao' \\ 'Department of Orthopedics, The \\ Affiliated Cancer Hospital of Zhengzhou \\ University and Henan Cancer Hospital, \\ Zhengzhou, Henan Province, 450008, \\ People's Republic of China; ${ }^{2}$ Department \\ of Immunotherapy, The Affiliated Cancer \\ Hospital of Zhengzhou University and \\ Henan Cancer Hospital, Zhengzhou, \\ Henan Province, 450008, People's \\ Republic of China
}

Correspondence: Jiaqiang Wang Department of Orthopaedics, The Affiliated Cancer Hospital of Zhengzhou University and Henan Cancer Hospital,

Zhengzhou, Henan Province, 450008,

People's Republic of China

Tel +86-|8737|8783|

Fax +86-37I-6596I505

Email doctorwangjiaqiang@|26.com
Purpose: Advanced clear cell sarcoma (CCS) is a rare subtype of sarcoma with few effective treatments. Evidence shows that apatinib is efficacious and safe for CCS. This study aimed to assess the safety and efficacy of apatinib and/or camrelizumab (a PD-1 inhibitor) in treating advanced CCS.

Methods: We retrospectively reviewed 12 patients with advanced CCS who received apatinib and/or camrelizumab therapy between November 2018 and July 2021. Standard descriptive statistics were employed for continuous variables and categorical variables (number and percentage).

Results: Of the 12 CCS patients, 3 had a partial response (PR), and 4 had stable disease (SD). Among the 5 patients treated with apatinib monotherapy, 1 PR and 2 SD were found, and the addition or replacement of camrelizumab after progressive disease (PD) did not work. In the 4 patients who received apatinib plus camrelizumab combination therapy, $1 \mathrm{PR}$ and 1 SD were found. All 3 patients who received camrelizumab first had PD, and 1 PR and 1 SD were found after adding apatinib. Grade 3 or 4 adverse events were significantly more common in the apatinib plus camrelizumab combination therapy than in the apatinib or camrelizumab monotherapy, and these included increased aspartate aminotransferase and increased alanine aminotransferase levels.

Conclusion: Apatinib has promising effectiveness for CCS. Camrelizumab efficacy for the treatment of clear cell sarcoma is inconclusive. The efficacy of apatinib and PD-1 inhibitors in CCS need to be further investigated in prospective clinical trials.

Keywords: clear cell sarcoma, apatinib, camrelizumab, sarcoma, tyrosine kinase inhibitor, PD-1 inhibitor

\section{Introduction}

Clear cell sarcoma (CCS) is an extremely rare sarcoma, accounting for approximately $1 \%$ of all soft tissue sarcomas (STSs), with approximately 400 new cases in China each year. ${ }^{1,2}$ CCS was originally named soft tissue melanoma because of its immunohistochemical, ultrastructural, and genomic predisposition to melanocyte differentiation., This designation is now obsolete because pathologists can now accurately identify clear cell sarcomas. ${ }^{1,5}$ CCS may originate anywhere in the body but more often in the extremities. The initial symptom is usually a slowly increasing painless mass with lymph node metastasis in the early to middle stages. ${ }^{3,4,6}$ Once lymph node metastasis occurs, CCS progression begins to accelerate, followed by widespread metastases to the lungs and/or other organs of the body. ${ }^{7,8}$ Surgery is the main treatment for early and 
middle stages CCS. ${ }^{1,9} \mathrm{CCS}$ is insensitive to chemotherapy and radiotherapy, ${ }^{1,10,11}$ resulting in a poor prognosis for advanced CCS, with a median overall survival (OS) of less than 1 year. $^{11-13}$

With the large-scale marketing and clinical application of targeted drugs, CCS, like other STSs, has many new treatment options. ${ }^{1,11,14}$ Of the many targeted therapies, the most influential are multi-target tyrosine kinase inhibitors (TKIs), ${ }^{1,15}$ and PD-1 inhibitors. ${ }^{16}$ Apatinib is a multi-target TKI that is marketed in China. It is widely used off-label for treating sarcomas in China, and its efficacy has been repeatedly confirmed. ${ }^{17}$ Camrelizumab is a PD-1 inhibitor marketed in China and is also widely used off-label for the treatment of sarcomas. ${ }^{18,19}$

As a major sarcoma diagnosis and treatment center in a province with a population of nearly 100 million in central China, we have rich experience in sarcoma diagnosis and treatment. ${ }^{20-22}$ We have also treated sarcoma patients with multi-targeted TKIs and/or PD1 inhibitors, some of which were CCS patients. ${ }^{21,23}$ In this study, we retrospectively collected and analyzed the clinical data of CCS patients who received either apatinib or camrelizumab, aimed to assess the safety and efficacy of apatinib and/or camrelizumab in the treatment of advanced CCS.

\section{Methods}

\section{Patients}

We retrospectively collected and analyzed the medical data of CCS patients treated with apatinib and/or camrelizumab between November 2018 and July 2021 at our institution. Written informed consent for off-label treatment was obtained from all the patients before treatment. This study was performed in accordance with the principles of the Declaration of Helsinki and the Institutional Review Board of the Affiliated Cancer Hospital of Zhengzhou University. The eligibility criteria were as follows: (1) histologically-confirmed CCS; (2) complete clinical data; (3) inoperable disease progression (recurrence or primary); (4) treatment with apatinib and/or camrelizumab; and (5) the target lesions were measurable according to the response evaluation criteria in solid tumors (RECIST).

\section{Evaluation of Safety and Efficacy}

Baseline information was collected and analyzed, including age, sex, presentation status of lesions, tumor location, tumor size, previous treatment history, date and dose of initial apatinib and camrelizumab administration, treatment interruption or discontinuation, and progression time. Efficacy was evaluated according to the RECIST criteria every 6 weeks using magnetic resonance imaging or computed tomography. Anti-tumor efficacy was categorized as complete response (CR), partial response (PR), stable disease (SD), or progressive disease (PD), according to the RECIST criteria. Response duration and adverse events (AEs) were also evaluated. Response duration was defined as the time from the occurrence of CR or PR to treatment to the occurrence of PD or death. AEs were assessed using the National Cancer Institute Common Terminology Criteria for Adverse Events, version 4.0.

\section{Statistical Analysis}

This study was a descriptive analysis. All data were analyzed using SPSS 21.0, and the corresponding figure was drawn using GraphPad Prism (version 8). Quantitative variables are presented as numerical values (percentages) and medians (ranges). Standard descriptive statistics were employed for continuous and categorical variables (numbers and percentages) to characterize patient demographics, treatment response, and AEs. Group-wise comparison was performed using the Chi-square test. All statistical analyses were two-sided, and $\mathrm{p}<0.05$ was considered statistically significant. The last date for the assessment of clinical outcomes was July 31, 2021.

\section{Results}

\section{Patient Characteristics}

From November 2018 to July 2021, a total of 12 patients with advanced CCS treated with apatinib and/or camrelizumab were identified. Basic patient characteristics are shown in Table 1 . The cohort included 6 men and 6 women. The average patient age was $42.00 \pm 14.73$ years. All patients had an Eastern Cooperative Oncology Group performance status of 0 or 1 and stage IV disease. The primary tumor site varied greatly and was distributed throughout the body. However, it was mainly in the extremities (as the primary tumor location was the thigh in two patients, hand in three patients, forearm in two patients, axillary region in one patient, scapular region in one patient, gluteal region in one patient, lower leg in one patient, and upper arm in one patient). Lymph node metastasis occurred first in all patients, and all patients had previously received doxorubicin or doxorubicin plus ifosfamide chemotherapy (Table 1).

Five of the $12 \mathrm{CCS}$ patients started treatment with apatinib monotherapy. After PD, two patients received a combination therapy of apatinib plus camrelizumab, and two patients discontinued apatinib and were replaced with camrelizumab 
Table I Patient Demographics and Characteristics

\begin{tabular}{|c|c|c|c|c|c|c|c|c|c|c|}
\hline $\begin{array}{l}\text { Patient } \\
\text { No. }\end{array}$ & Sex & $\begin{array}{c}\text { Age } \\
\text { (Years) }\end{array}$ & $\begin{array}{c}\text { ECOG } \\
\text { PS }\end{array}$ & Stage & $\begin{array}{l}\text { Primary } \\
\text { Site }\end{array}$ & $\begin{array}{l}\text { Metastatic } \\
\text { Site }\end{array}$ & $\begin{array}{l}\text { Previous } \\
\text { Treatment }\end{array}$ & $\begin{array}{c}\text { Sequence of } \\
\text { Administration }\end{array}$ & $\begin{array}{c}\text { Best } \\
\text { Response }\end{array}$ & $\begin{array}{l}\text { Response } \\
\text { Duration } \\
\text { (Months) }\end{array}$ \\
\hline I & Female & 30 & 0 & IV & Thigh & $\begin{array}{l}\text { Lymph } \\
\text { nodes }\end{array}$ & $A+I$ & $\begin{array}{l}\text { Start with } A P \text {, } \\
\text { and add } C \text { after } \\
\text { PD. }\end{array}$ & PR & 8.5 \\
\hline 2 & Female & 27 & 0 & IV & Hand & Lung & $A+I$ & $\begin{array}{c}\text { Start with AP, } \\
\text { and add } C \text { after } \\
\text { PD. }\end{array}$ & PD & 0 \\
\hline 3 & Male & 43 & 0 & IV & Hand & $\begin{array}{l}\text { Lymph } \\
\text { nodes }\end{array}$ & $A+1$ & $\begin{array}{l}\text { Start with } A P, \\
\text { and switched to } \\
\text { C after PD }\end{array}$ & SD & 4 \\
\hline 4 & Female & 58 & 1 & IV & Forearm & $\begin{array}{l}\text { Lymph } \\
\text { nodes }\end{array}$ & $A+I$ & $\begin{array}{l}\text { Start with } A P, \\
\text { and switched to } \\
\text { C after PD }\end{array}$ & SD & 6.5 \\
\hline 5 & Female & 49 & 0 & IV & Thigh & $\begin{array}{l}\text { Lymph } \\
\text { nodes }\end{array}$ & $A+I$ & $\begin{array}{l}\text { Start with } A P, \\
\text { and switched to } \\
\text { C after PD }\end{array}$ & PD & 0 \\
\hline 6 & Male & 62 & 0 & IV & $\begin{array}{l}\text { Axillary } \\
\text { region }\end{array}$ & $\begin{array}{l}\text { Lymph } \\
\text { nodes }\end{array}$ & A & $\begin{array}{l}\text { Start with } C \text {, and } \\
\text { add } A P \text { after } P D\end{array}$ & PD & 0 \\
\hline 7 & Male & 28 & I & IV & $\begin{array}{l}\text { Scapular } \\
\text { region }\end{array}$ & $\begin{array}{l}\text { Lymph } \\
\text { nodes }\end{array}$ & A & $\begin{array}{l}\text { Start with } C \text {, and } \\
\text { add AP after PD }\end{array}$ & PR & 11.5 \\
\hline 8 & Male & 61 & I & IV & Forearm & $\begin{array}{l}\text { Lymph } \\
\text { nodes }\end{array}$ & $A+1$ & $\begin{array}{l}\text { Start with } C \text {, and } \\
\text { add } A P \text { after } P D\end{array}$ & SD & 6 \\
\hline 9 & Male & 42 & I & IV & $\begin{array}{l}\text { Gluteal } \\
\text { region }\end{array}$ & $\begin{array}{l}\text { Lymph } \\
\text { nodes }\end{array}$ & $A+I$ & $\begin{array}{c}\text { AP in parallel } \\
\text { with } C\end{array}$ & PD & 0 \\
\hline 10 & Female & 54 & 0 & IV & Lower leg & $\begin{array}{l}\text { Lymph } \\
\text { nodes }\end{array}$ & A & $\begin{array}{c}\text { AP in parallel } \\
\text { with } C\end{array}$ & PD & 0 \\
\hline II & Male & 21 & 0 & IV & $\begin{array}{l}\text { Upper } \\
\text { arm }\end{array}$ & $\begin{array}{l}\text { Lymph } \\
\text { nodes }\end{array}$ & $A+I$ & $\begin{array}{c}A P \text { in parallel } \\
\text { with } C\end{array}$ & SD & 2 \\
\hline 12 & Female & 29 & 0 & IV & Hand & $\begin{array}{l}\text { Lymph } \\
\text { nodes }\end{array}$ & $A+1$ & $\begin{array}{c}\text { AP in parallel } \\
\text { with } C\end{array}$ & $P R$ & 5 \\
\hline
\end{tabular}

Abbreviations: ECOG PS, Eastern Cooperative Oncology Group performance status; A, adriamycin; I, ifosfamide; AP, apatinib; C, camrelizumab; PD, progressive disease; $\mathrm{PR}$, partial response; SD, stable disease.

monotherapy. Three patients started with camrelizumab monotherapy and changed to apatinib plus camrelizumab combination therapy when PD occurred. Four patients received apatinib plus camrelizumab combination therapy.

\section{Treatment Outcomes}

Of the 12 CCS patients, none had a CR. Three patients had PR, and four patients had SD (Table 1, Figure 1). As shown in Table 1, of the 3 patients with PR, patient 1 developed PR after apatinib monotherapy, and the response lasted for 8.5 months, and camrelizumab was ineffective after PD. Patient 7 had no response to camrelizumab monotherapy and had PR after adding apatinib, and the response lasted 11.5 months. Patient 12 achieved PR after treatment with apatinib plus camrelizumab combination therapy, and the response lasted 5 months. The median progression-free survival of all the 12 patients was 3 months (95\% CI, 1.3 - NA months) (Figure 2).

Table 2 summarizes the effects of different administration sequences. Among the five patients treated with apatinib monotherapy, 1 PR and 2 SD were identified, and the addition or replacement of camrelizumab after PD did not work. In the 


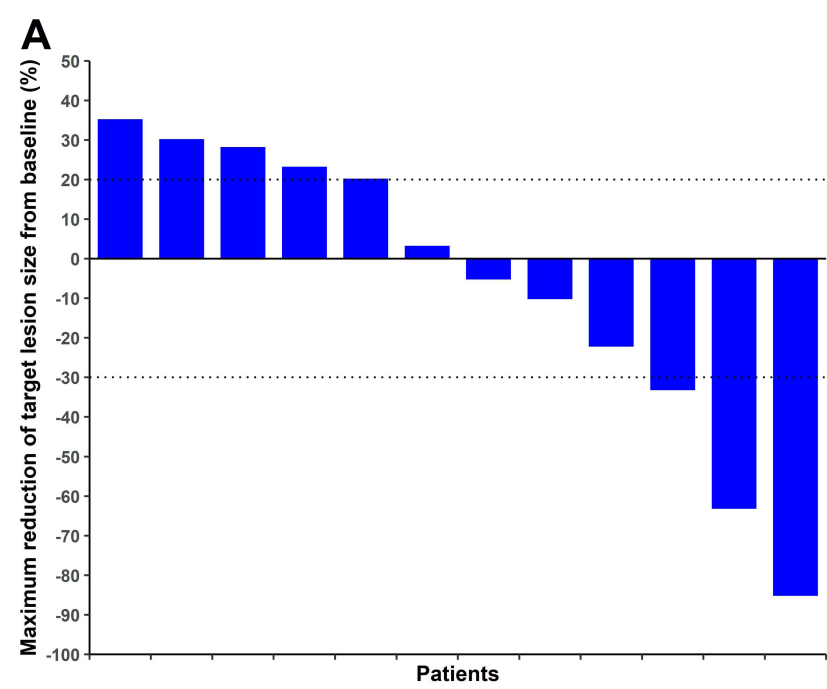

\section{B}

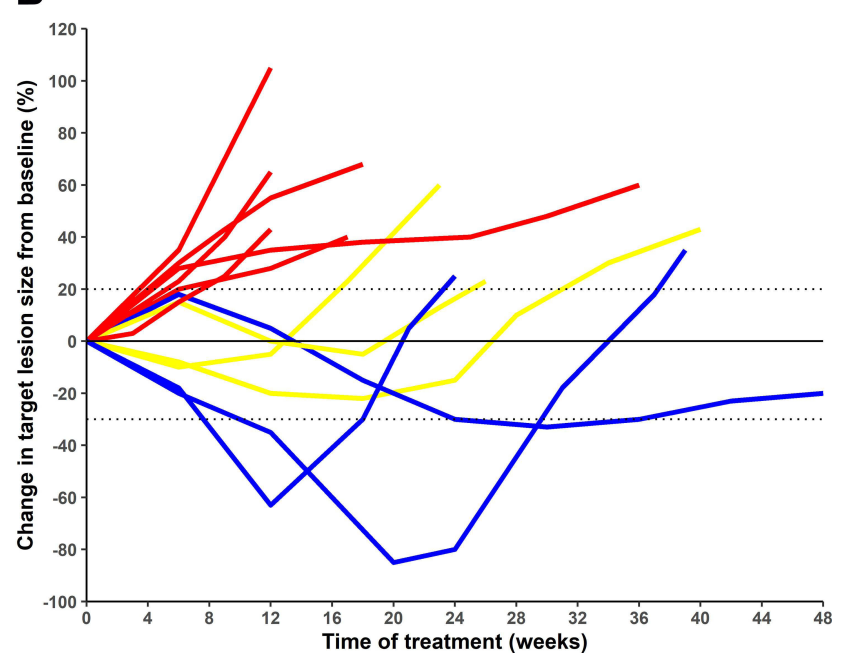

Figure I Changes in target lesions in patients treated with apatinib and/or camrelizumab. (A) Maximum reduction of target lesion size from baseline in patients with advanced clear cell sarcoma (CCS) treated with apatinib and/or camrelizumab. As evaluated according to the Response Evaluation Criteria in Solid Tumors. Version I.I, no patients had a complete response. Three patients had a partial response, and four patients had stable disease. (B) Changes from baseline in target lesion size after apatinib and/or camrelizumab treatment in 12 patients with advanced CCS. Those that have been reduced by $30 \%$ or more are shown in green line, those that have not been reduced and increased by $20 \%$ or more are shown in red line, and those that have been reduced by less than $30 \%$ and then increased are shown in yellow line.

four patients who received apatinib plus camrelizumab combination therapy, $1 \mathrm{PR}$ and $1 \mathrm{SD}$ were identified. All three patients who received camrelizumab first had PD, and 1 PR and $1 \mathrm{SD}$ were found after adding apatinib.

\section{Toxicity and Safety}

Overall, treatment with apatinib and camrelizumab was safe (Table 3). Most patients experienced grades 1 or 2 AEs, a few patients experienced grades 3 or 4 AEs, and no drug-related deaths occurred. To better describe AEs with apatinib and

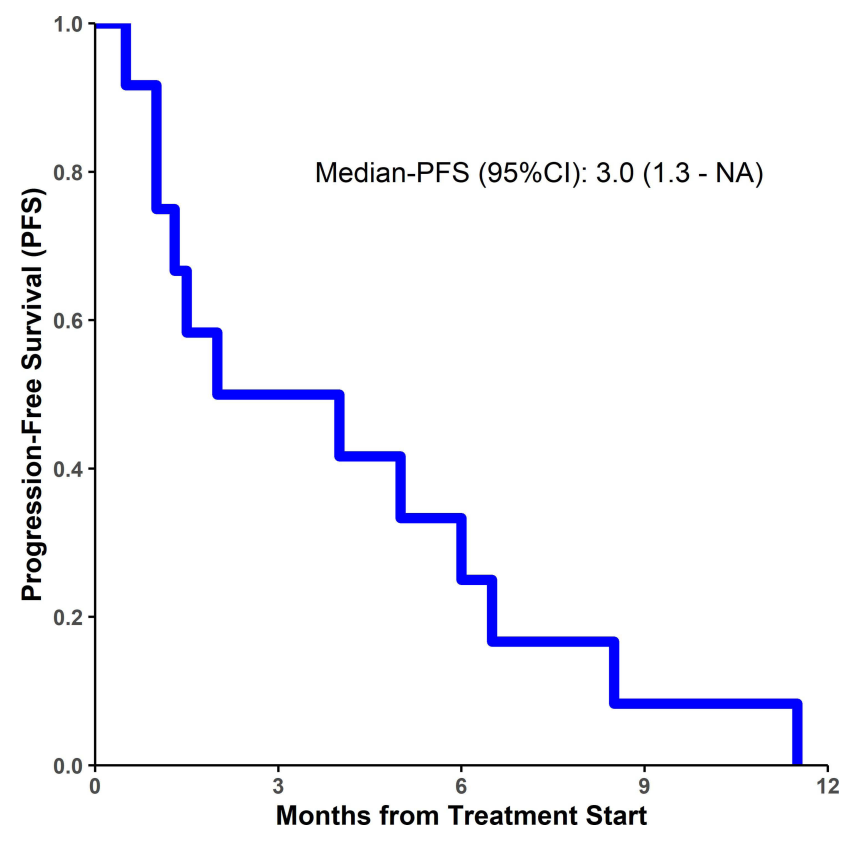

Figure 2 Kaplan-Meier estimates of progression-free survival for all the 12 patients with clear cell sarcoma.

camrelizumab, we divided the patients into the apatinib group (5 patients receiving apatinib monotherapy), the camrelizumab group (6 patients receiving camrelizumab), and the apatinib plus camrelizumab group ( 9 patients receiving the combination therapy) (Table 3). Grade 3 or 4 AEs were significantly more common in the apatinib plus camrelizumab group than in the apatinib or camrelizumab group, and these included increased aspartate aminotransferase $(p=0.023)$ and increased alanine aminotransferase $(\mathrm{p}=0.017)$ (Table 3$)$.

\section{Discussion}

In this study, we retrospectively reviewed and analyzed the clinical data of 12 CCS patients who received apatinib and/or

Table 2 Patient Responses to Different Treatment

\begin{tabular}{|l|c|c|c|c|}
\hline \multirow{2}{*}{ Treatment } & \multicolumn{4}{|c|}{ Number of Patients } \\
\cline { 2 - 5 } & CR & PR & SD & PD \\
\hline AP $(n=5)$ & 0 & I & 2 & 2 \\
\hline C after the PD of AP (n=3) & 0 & 0 & 0 & 3 \\
\hline C + AP after the PD of AP $(n=2)$ & 0 & 0 & 0 & 2 \\
\hline C (n=3) & 0 & 0 & 0 & 3 \\
\hline C + AP after the PD of C (n=3) & 0 & I & I & I \\
\hline C + AP $(n=4)$ & 0 & I & I & 2 \\
\hline
\end{tabular}

Abbreviations: $C R$, complete response; $P R$, partial response; SD, stable disease; PD, progressive disease; AP, apatinib; C, camrelizumab. 
Table 3 Grade 3 or 4 Adverse Events

\begin{tabular}{|l|c|c|c|c|}
\hline Characteristics & Apatinib (n=5) & Camrelizumab (n=6) & Apatinib Plus Camrelizumab (n=9) & P-value \\
\hline Hypertension & I & 0 & I & I \\
\hline Hand-foot syndrome & I & 0 & I & 0.539 \\
\hline Diarrhea & 0 & I & 6 & 0.639 \\
\hline Increased aspartate aminotransferase & 0 & I & 5 & 0.023 \\
\hline Increased alanine aminotransferase & 0 & 0 & 2 & 0.017 \\
\hline Decreased neutrophil count & 0 & 0 & 2 & 0.257 \\
\hline Increased blood bilirubin & 0 & 0 & 0.257 \\
\hline
\end{tabular}

Note: Data are presented as numbers.

camrelizumab. Three patients achieved PR with a response time of 8.5 months, 11.5 months, and 5 months, respectively. Furthermore, the biggest safety problem of apatinib combined with camrelizumab was the increase in aspartate aminotransferase and alanine aminotransferase levels.

Including this study, CCS has been reported to respond to treatment with apatinib, sunitinib, anlotinib, and pazopanib. ${ }^{15,24,25}$ This phenomenon is worthy of further research. These target drugs belong to a class of multi-target TKIs with VEGFR (vascular endothelial growth factor)-2 as the main target, and their targets are shown in Table 4. Based on the aggregated results, we can conclude that VEGFRs are an important set of targets for the treatment of CCS. Therefore, it can be inferred that other multi-target TKIs with VEGFR-2 as the main target can also achieve some efficacy in treating CCS. Moreover, a 2017 clinical trial showed that crizotinib also had some effect on CCS. ${ }^{14}$ The main target of crizotinib was MET (Table 4). This suggests that MET may also be a key target for CCS therapy. Thus, we conclude that another multi- target TKI, cabozantinib, may be more effective in treating CCS because it has the most comprehensive targets, including VEGFRs and MET (Table 4). Prospective clinical trials of cabozantinib for CCS are warranted.

In this study, PR was observed in patients receiving apatinib alone or in combination, while no effective response was observed in patients receiving camrelizumab alone or in combination with camrelizumab after apatinib resistance. This confirms that apatinib does work in a subset of CCS patients but does not confirm the effectiveness of camrelizumab. We suspected that camrelizumab did not work. The results of numerous clinical trials to date indicate that PD-1 inhibitor monotherapy has minimal effectiveness in STSs. ${ }^{16,31,32}$ Although the combination of multi-target TKIs and PD-1 inhibitors may improve the efficacy of these two drugs in STS, ${ }^{33,34}$ there are many subtypes of STS, and the combination of multi-target TKIs and PD-1 inhibitors is only effective in a few subtypes of STS. Moreover, no evidence has been reported that PD-1

Table 4 Sensitive Targets of Apatinib, Pazopanib, Anlotinib, Sunitinib, Crizotinib, and Cabozantinib

\begin{tabular}{|c|c|c|c|c|c|c|c|c|c|c|}
\hline \multirow[t]{2}{*}{ TKIs } & \multicolumn{9}{|c|}{ PTKs \& IC so $(\mathrm{nM}$, Mean) } & \multirow[t]{2}{*}{ References } \\
\hline & VEGFR I & VEGFR2 & VEGFR3 & KIT & RET & PDGFR $\alpha$ & PDGFRß & FGFR I & MET & \\
\hline Apatinib & 70 & 1 & - & 429 & 13 & $>1000$ & - & $>10,000$ & - & {$[26]$} \\
\hline Pazopanib & 10 & 30 & 47 & 74 & - & 71 & 84 & 140 & - & {$[27]$} \\
\hline Anlotinib & 26.9 & 0.2 & 0.7 & 14.8 & - & 167 & - & 40.4 & $>2000$ & [28] \\
\hline Sunitinib & 71.5 & 4 & 15.7 & II & 72 & 13 & 7.7 & 510 & $>2000$ & {$[28]$} \\
\hline Crizotinib & - & - & - & - & - & - & - & - & 11 & [29] \\
\hline Cabozantinib & 12 & 0.035 & 6 & 4.6 & 5.2 & - & 234 & 5294 & 12 & [30] \\
\hline
\end{tabular}

Abbreviations: TKI, tyrosine kinase inhibitor; RTKs, receptor tyrosine kinases. 
inhibitors alone or in combination with other therapies show activity in CCS. In summary, based on the results of this study and the currently available evidence, we speculate that the efficacy of PD-1 inhibitors in CCS is minimal.

This study suggests the safety of apatinib in combination with camrelizumab for the treatment of CCS. In this study, AEs were rare when apatinib or camrelizumab was used alone. The incidence of grades 3 or 4 AEs increased significantly when apatinib was combined with camrelizumab. The most common grade 3 and above AEs were increased transaminase levels. These AEs caused patients to be unable to continue using camrelizumab and require glucocorticoids to inhibit the pharmacological effects of camrelizumab. This may also explain why apatinib plus camrelizumab was not effective in this study.

It should be noted that patients treated with the combination regimen of apatinib and camrelizumab did not present with severe aminotransferase elevations in other tumor species. ${ }^{35-37}$ This may be related to the higher dose of apatinib used in this study $(500 \mathrm{mg} /$ day in this study versus $250-375 \mathrm{mg} /$ day in other studies). This suggests that we need to lower the dose of apatinib in future studies or when using this combination regimen.

There were several limitations to this study. First, this study was retrospective in nature, with a small sample size and a lack of a control group. These limitations were due to the rareness of CCS. Second, the disordered use of drugs. Treatment with camrelizumab was unplanned in all cases in this study. We do not yet know the optimal order and scenarios for using multi-target TKIs and PD-1 inhibitors. This is a problem that doctors around the world are now facing when treating sarcomas. This needs to be confirmed by a large number of prospective clinical trials.

\section{Conclusion}

Apatinib has promising effectiveness for CCS. The efficacy of camrelizumab for the treatment of clear cell sarcoma is inconclusive. The efficacy of apatinib and PD-1 inhibitors in CCS needs to be further investigated in prospective clinical trials.

\section{Ethical Statement}

This retrospective study was approved by the Ethics Committee of the Henan Cancer Hospital in China, and written informed consent was obtained from each patient prior to all treatment procedures. Patients were informed that the medical records were stored by the hospital and potentially used for scientific research and that privacy would be maintained. All procedures performed in studies involving human participants were in accordance with the ethical standards of the institutional and/or national research committee and with the 1964 Helsinki declaration and its later amendments or comparable ethical standards.

\section{Author Contributions}

All authors made a significant contribution to the work reported, whether that is in the conception, study design, execution, acquisition of data, analysis and interpretation, or in all these areas; took part in drafting, revising or critically reviewing the article; gave final approval of the version to be published; have agreed on the journal to which the article has been submitted; and agree to be accountable for all aspects of the work.

\section{Disclosure}

The authors declare they have no competing interests in this work.

\section{References}

1. Ibrahim RM, Steenstrup Jensen S, Juel J. Clear cell sarcoma-a review. J Orthop. 2018;15(4):963-966. doi:10.1016/j.jor.2018.08.039

2. Yang $Z$, Zheng R, Zhang $S$, et al. Incidence, distribution of histological subtypes and primary sites of soft tissue sarcoma in China. Cancer Biol Med. 2019;16(3):565-574. doi:10.20892/j.issn.20953941.2019 .0041

3. Clark MA, Johnson MB, Thway K, et al. Clear cell sarcoma (melanoma of soft parts): the Royal Marsden Hospital experience. Eur J Surg Oncol. 2008;34(7):800-804. doi:10.1016/j.ejso.2007.10.006

4. Malchau SS, Hayden J, Hornicek F, et al. Clear cell sarcoma of soft tissues. J Surg Oncol. 2007;95(6):519-522. doi:10.1002/jso.20730

5. Yang L, Chen Y, Cui T, et al. Identification of biomarkers to distinguish clear cell sarcoma from malignant melanoma. Hum Pathol. 2012;43(9):1463-1470. doi:10.1016/j.humpath.2011.10.022

6. Hocar O, Le Cesne A, Berissi S, et al. Clear cell sarcoma (malignant melanoma) of soft parts: a clinicopathologic study of 52 cases. Dermatol Res Pract. 2012;2012:984096. doi:10.1155/2012/984096

7. Ipach I, Mittag F, Kopp HG, et al. Clear-cell sarcoma of the soft tissue-a rare diagnosis with a fatal outcome. Eur $J$ Cancer Care (Engl). 2012;21(3):412-420. doi:10.1111/j.1365-2354.2011.01318.x

8. Blazer DG, Lazar AJ, Xing Y, et al. Clinical outcomes of molecularly confirmed clear cell sarcoma from a single institution and in comparison with data from the Surveillance, Epidemiology, and End Results registry. Cancer. 2009;115:2971-2979. doi:10.1002/cncr.24322

9. Cornillie J, van Cann T, Wozniak A, et al. Biology and management of clear cell sarcoma: state of the art and future perspectives. Expert Rev Anticancer Ther. 2016;16(8):839-845. doi:10.1080/147371 40.2016.1197122

10. Jones RL, Constantinidou A, Thway K, et al. Chemotherapy in clear cell sarcoma. Med Oncol. 2011;28(3):859-863. doi:10.1007/s12032010-9502-7

11. Li AB, Jiang BJ, Wang HH, et al. Prognostic factors for survival in patients with clear cell sarcoma: an analysis of the Surveillance, Epidemiology, and End Results (SEER) database. Med Sci Monit. 2019;25:6950-6956. doi:10.12659/MSM.916705 
12. Chen S, Luo P, Yang L, et al. Prognostic analysis of surgically treated clear cell sarcoma: an analysis of a rare tumor from a single center. Int J Clin Oncol. 2019;24(12):1605-1611. doi:10.1007/s10147-01901487-x

13. Gonzaga MI, Grant L, Curtin C, et al. The epidemiology and survivorship of clear cell sarcoma: a National Cancer Database (NCDB) review. J Cancer Res Clin Oncol. 2018;144(9):1711-1716. doi:10.1007/s00432-018-2693-6

14. Schoffski P, Wozniak A, Stacchiotti S, et al. Activity and safety of crizotinib in patients with advanced clear-cell sarcoma with MET alterations: European Organization for Research and Treatment of Cancer phase II trial 90101 'CREATE'. Ann Oncol. 2017;28 (12):3000-3008. doi:10.1093/annonc/mdx527

15. Chi Y, Fang Z, Hong X, et al. Safety and efficacy of anlotinib, a multikinase angiogenesis inhibitor, in patients with refractory metastatic soft-tissue sarcoma. Clin Cancer Res. 2018;24(21):5233-5238. doi:10.1158/1078-0432.CCR-17-3766

16. Siozopoulou V, Domen A, Zwaenepoel K, et al. Immune checkpoint inhibitory therapy in sarcomas: is there light at the end of the tunnel? Cancers (Basel). 2021;13(2):360. doi:10.3390/cancers 13020360

17. Yang QK, Chen T, Wang SQ, et al. Apatinib as targeted therapy for advanced bone and soft tissue sarcoma: a dilemma of reversing multidrug resistance while suffering drug resistance itself. Angiogenesis. 2020;23(3):279-298. doi:10.1007/s10456-020-09716-y

18. Xie L, Xu J, Sun X, et al. Apatinib plus camrelizumab (anti-PD1 therapy, SHR-1210) for advanced osteosarcoma (APFAO) progressing after chemotherapy: a single-arm, open-label, phase 2 trial. $J$ Immunother Cancer. 2020;8(1):e000798. doi:10.1136/jitc-2020000798

19. Xu Z, Zhang Y, Yu YH. Successful treatment of advanced alveolar soft part sarcoma with camrelizumab combined with apatinib: a case report. Ann Palliat Med. 2021;10:785-792. doi:10.21037/apm-20-2275

20. Tian Z, Wang X, Liu Z, et al. Safety and efficacy of combination therapy with apatinib and doxorubicin in metastatic soft tissue sarcomas: an observational study from multiple institutions. Cancer Manag Res. 2019;11:5293-5300. doi:10.2147/CMAR.S207150

21. Tian Z, Liu H, Zhang F, et al. Retrospective review of the activity and safety of apatinib and anlotinib in patients with advanced osteosarcoma and soft tissue sarcoma. Invest New Drugs. 2020;38 (5):1559-1569. doi:10.1007/s10637-020-00912-7

22. Tian Z, Yang Y, Yang Y, et al. High cumulative doxorubicin dose for advanced soft tissue sarcoma. BMC Cancer. 2020;20(1):1139. doi:10.1186/s12885-020-07663-x

23. Tian Z, Yang Y, Yang J, et al. Safety and efficacy of PD-1 inhibitors plus chemotherapy in advanced soft tissue sarcomas: a retrospective study. Cancer Manag Res. 2020;12:1339-1346. doi:10.2147/CMAR. S237300

24. Urakawa H, Kawai A, Goto T, et al. Phase II trial of pazopanib in patients with metastatic or unresectable chemoresistant sarcomas a Japanese Musculoskeletal Oncology Group study. Cancer Sci. 2020;111:3303-3312. doi:10.1111/cas.14542

25. Stacchiotti S, Grosso F, Negri T, et al. Tumor response to sunitinib malate observed in clear-cell sarcoma. Ann Oncol. 2010;21 (5):1130-1131. doi:10.1093/annonc/mdp611
26. Tian S, Quan H, Xie C, et al. YN968D1 is a novel and selective inhibitor of vascular endothelial growth factor receptor-2 tyrosine kinase with potent activity in vitro and in vivo. Cancer Sci. 2011;102(7):1374-1380. doi:10.1111/j.1349-7006.2011.01939.x

27. Hamberg P, Verweij J, Sleijfer S. (Pre-)clinical pharmacology and activity of pazopanib, a novel multikinase angiogenesis inhibitor. Oncologist. 2010;15(6):539-547. doi:10.1634/theoncologist.2009-0274

28. Xie C, Wan X, Quan H, et al. Preclinical characterization of anlotinib, a highly potent and selective vascular endothelial growth factor receptor-2 inhibitor. Cancer Sci. 2018;109(4):1207-1219. doi:10.111 $1 /$ cas. 13536

29. Tanizaki J, Okamoto I, Okamoto K, et al. MET tyrosine kinase inhibitor crizotinib (PF-02341066) shows differential antitumor effects in non-sm all cell lung cancer according to MET alterations. $J$ Thorac Oncol. 2011;6(10):1624-1631. doi:10.1097/JTO.0b013 e31822591e9

30. Roy S, Narang BK, Rastogi SK, et al. A novel multiple tyrosine-kinase targeted agent to explore the future perspectives of anti-angiogenic therapy for the treatment of multiple solid tumors: cabozantinib. Anticancer Agents Med Chem. 2015;15(1):37-47. doi:10.2174/1871520614666140902153840

31. Tawbi HA, Burgess $M$, Bolejack V, et al. Pembrolizumab in advanced soft-tissue sarcoma and bone sarcoma (SARC028): a multicentre, two-cohort, single-arm, open-label, phase 2 trial. Lancet Oncol. 2017;18:1493-1501. doi:10.1016/S1470-2045(17) 30624-1

32. D'Angelo SP, Mahoney MR, Van Tine BA, et al. Nivolumab with or without ipilimumab treatment for metastatic sarcoma (Alliance A091401): two open-la bel, non-comparative, randomised, phase 2 trials. Lancet Oncol. 2018;19:416-426. doi:10.1016/S1470-2045(18) 30006-8

33. Wilky BA, Trucco MM, Subhawong TK, et al. Axitinib plus pembrolizumab in patients with advanced sarcomas including alveolar soft-part sarcoma: a single-centre, single-arm, phase 2 trial. Lancet Oncol. 2019;20(6):837-848. doi:10.1016/S1470-2045(19)30153-6

34. Martin-Broto J, Hindi N, Grignani G, et al. Nivolumab and sunitinib combination in advanced soft tissue sarcomas: a multicenter, single-arm, phase Ib/II trial. J Immunother Cancer. 2020;8(2): e001561. doi:10.1136/jitc-2020-001561

35. Lan C, Shen J, Wang Y, et al. Camrelizumab plus apatinib in patients with advanced cervical cancer (CLAP): a multicenter, open-label, single-arm, phase II trial. J Clin Oncol. 2020;38(34):4095-4106. doi: 10.1200/JCO.20.01920

36. Fan Y, Zhao J, Wang Q, et al. Camrelizumab plus apatinib in extensive-stage SCLC (PASSION): a multicenter, two-stage, phase 2 trial. J Thorac Oncol. 2020;16(2):299-309. doi:10.1016/j. jtho.2020.10.002

37. Xu J, Shen J, Gu S, et al. Camrelizumab in combination with apatinib in patients with advanced hepatocellular carcinoma (RESCUE): a nonrandomized, open-label, phase II trial. Clin Cancer Res. 2020;27(4):1003-1011. doi:10.1158/1078-0432.CCR-20-2571
Cancer Management and Research

\section{Publish your work in this journal}

Cancer Management and Research is an international, peer-reviewed open access journal focusing on cancer research and the optimal use of preventative and integrated treatment interventions to achieve improved outcomes, enhanced survival and quality of life for the cancer patient.
The manuscript management system is completely online and includes a very quick and fair peer-review system, which is all easy to use. Visit http://www.dovepress.com/testimonials.php to read real quotes from published authors. 